Article

\title{
Suicidal Ideation and Sense of Community in Faith Communities
}

\author{
Karen Mason* (D), W. Blake Martin and Esther Kim \\ Counseling Department, Gordon-Conwell Theological Seminary, 130 Essex St., South Hamilton, MA 01982, USA; \\ wmartin1@gordonconwell.edu (W.B.M.); ekim14@gordonconwell.edu (E.K.) \\ * Correspondence: kmason@gordonconwell.edu
}

Received: 11 December 2017; Accepted: 26 January 2018; Published: 30 January 2018

\begin{abstract}
Previous studies have found that religion and spirituality (R/S) are related to less suicidal ideation (SI), fewer suicide attempts and fewer suicide deaths and that an absence of social support is associated with SI, suicide attempts, and suicide death. 745 Catholic, Jewish, and Protestant congregants completed an online survey measuring their sense of community (SOC) in their faith community, overall belonging and SI. SOC was weakly related to SI. Congregants attending more than one service per week reported more SI and more importance to feel a SOC. Jewish and Hispanic congregants reported more SI. Unmarried congregants reported lower overall belonging, more SOC and more SI, suggesting that people apportion their sense of connectedness differently. Future studies might examine the relationship of SOC to suicide attempts and deaths and how a faith community might confer SOC differently from a non-religious/non-spiritual community.
\end{abstract}

Keywords: suicide; sense of community; religion; spirituality; faith community; congregants; belongingness

Religion and spirituality (R/S) are associated with greater physical and mental health (Koenig et al. 2012) including less suicidal ideation (Bearman and Moody 2004; Blackmore et al. 2008; Cohen et al. 2008; Cook et al. 2002; Greening and Stoppelbein 2002; Pienaar et al. 2007), fewer suicide attempts (Burshtein et al. 2016; Nonnemaker et al. 2003; Thompson et al. 2007), and fewer suicide deaths (Barranco 2016; Hilton et al. 2002; Nisbet et al. 2000; VanderWeele et al. 2016). However, the relationship between R/S and suicidal behaviors is complex (Lawrence et al. 2016). R/S may not be protective in all populations (Lawrence et al. 2016; O'Reilly and Rosato 2015) and under all conditions. For example, religious faith has been found to be significantly and negatively related to suicidal behavior only at low levels of family support (Wang et al. 2016). Meaning in life differentiated between suicidal and non-suicidal religious youth (Wilchek-Aviad and Malka 2016). In addition, gender differences have been found with women reporting higher levels of SI (Piscopo et al. 2016) and religion and spirituality being more protective among women in some studies (Kralovec et al. 2017) but not all (Kazi and Naidoo 2016).

In this study, we investigated the relationship between congregants' sense of community in their faith community and suicidal ideation, which is a focus on religion. While religion and spirituality are overlapping constructs, they are distinct. Religion refers to "affiliation with an organization that is guided by shared beliefs and practices" and spirituality refers to "an individual's internal sense of connection to, or search for, the sacred" (Vieten et al. 2013, p. 136). This study is an investigation of sense of community in a faith community, a type of protection conferred by religion which may differ from other types of protections including those conferred by spirituality. This study's focus on religion is grounded in Durkheim (1897) theory of social integration and suicidal behavior. He theorized that the higher suicide rates among Protestants was related to lower social integration in their faith communities.

This study's focus on sense of community and sense of belonging is further grounded in the substantial evidence linking social support to physical (Holt-Lunstad et al. 2017) and psychological 
well-being (Cohen and Wills 1985; Maulik et al. 2011; Moak and Agrawal 2010; Morton et al. 2017). Social integration in a congregation is associated with life satisfaction (Lim and Putnam 2010). An absence of social support is associated with suicidal behavior including suicidal ideation (Chioqueta and Stiles 2007), suicide attempts (Kleiman and Liu 2013), and suicide death (Tsai et al. 2015). Social support is protective against suicide even apart from R/S (Rasic et al. 2009), and in fact, more frequent attendance at religious activities was associated with decreased current suicidal ideation, a relationship which remained significant when social support was added to the model (Rushing et al. 2013).

Sense of community (SOC) is a community level variable (Kuo et al. 1998) which has been measured in the workplace (Mahan et al. 2002) and in religious communities (Kissil and Itzhaky 2015; Miers and Fisher 2002). SOC is defined as "a feeling that members have of belonging, a feeling that members matter to one another and to the group, and a shared faith that members' needs will be met through commitment to be together" (McMillan and Chavis 1986, p. 9). SOC includes four elements: integration and fulfillment of needs (that one's needs will be met by membership in the group), membership (a feeling of belonging and relatedness), influence (a sense of mattering and making a difference), and emotional connection (that members share similar experiences). Sense of belonging to a community has been associated with positive mental health (Kitchen et al. 2012) and low sense of community belonging with higher risk of suicidal ideation (McConnell et al. 2016). The U.S. Congregational Life Survey (2001) found that sense of belonging differentiated the top 20\% spiritually vital congregations from other congregations (Woolever and Bruce 2004, p. 19), with 58\% of worshipers reporting "their sense of belonging to this congregation is strong and growing" (ibid., p. 48) (S. Barnett, Director, US Congregational Life survey, personal communication 6 June 2017). In the USCLS, sense of belonging depended on network embeddedness which was affected by size of congregation, frequency and length of attendance, and ideological unity (Stroope and Baker 2014).

According to Joiner (2005) interpersonal theory of suicidal behavior, thwarted belongingness (a sense of low belonging or social alienation) is an emotionally-painful experience that is associated with suicidal behaviors including suicidal ideation (Conner et al. 2007; Joiner et al. 2006, 2009; You et al. 2011; Van Orden et al. 2008). In this study we hypothesize that (1) high SOC will be related to less suicidal ideation; (2) SOC and belonging will be positively related; and (3) high belonging will be related to less suicidal ideation. A fourth research question regarding differences in SOC, belonging, and suicidal ideation between genders and among three religious traditions (Catholicism, Judaism, and Protestantism) guided further inquiry.

\section{Materials and Methods}

\subsection{Participants}

Using personal networks including a military chaplain trainer's networks, professors from several seminaries, a northeastern seminary's alumni association list, the Suicide Prevention Resource Center's list of suicide prevention contacts in 50 U.S. states, contacts from an organization that trains faith communities in suicide prevention, a Jewish newspaper, clergy participants from previous studies, and internet synagogue/church locators for all four U.S. Census regions, we asked individuals including clergy to distribute a link to an online survey hosted by Survey Monkey. Over seven months, we invited any Catholic, Jewish, and Protestant 18-year-old or older congregant who currently attends a faith community at least 2-3 services per month to participate.

The demographic characteristics (see Table 1) of this convenience sample of 745 congregants generally compare favorably to other congregational samples (U.S. Congregational Life Survey 2001; Faith Communities Today 2010; National Survey of Congregations) though, in this sample, White, married and Protestant respondents were overrepresented. 
Table 1. Demographics of participants.

\begin{tabular}{|c|c|}
\hline Demographic Characteristics & Participants \\
\hline Age & $\begin{array}{l}\mathrm{M}=52.88(\mathrm{SD}=16.02) \\
\text { Range: } 21-91 \text { years old }\end{array}$ \\
\hline Gender & Female: $64 \%(n=449)$ Male: $35.86 \%(n=251)$ \\
\hline Race & $\begin{array}{l}\text { American Indian: } 1.58 \%(n=11) \\
\text { Asian: } 4.4 \%(n=31) \\
\text { African American or Black: } 4.6 \%(n=32) \\
\text { Pacific Islander: } 0.6 \%(n=4) \\
\text { Multiple races: } 0.4 \%(n=3) \\
\text { White: } 89.11 \%(n=622)\end{array}$ \\
\hline Ethnicity & Hispanic: $3.8 \%(n=26)$ \\
\hline Marital status & $\begin{array}{l}\text { Divorced: } 5.73 \%(n=40) \\
\text { Married: } 75.64 \%(n=528) \\
\text { Never married: } 13.47 \%(n=94) \\
\text { Separated: } 0.72 \%(n=5) \\
\text { Widowed: } 4.3 \%(n=30)\end{array}$ \\
\hline U.S. Census Region & $\begin{array}{l}\text { Midwest: } 17 \%(n=119) \\
\text { Northeast: } 38.29 \%(n=268) \\
\text { South: } 26.43 \%(n=185) \\
\text { West: } 16 \%(n=112)\end{array}$ \\
\hline Religion & $\begin{array}{c}\text { Catholic: } 8.47 \%(n=53) \\
\text { Jewish: } 5.91 \%(n=37) \\
\text { Protestant: } 85.62 \%(n=536) \\
\text { Other (included 19 Mormons, } 1 \text { Buddhist, } 1 \text { Taoist, and } \\
51 \text { other Protestants): } 10.32 \%(n=72)\end{array}$ \\
\hline Most Represented Denominations & $\begin{array}{c}\text { Baptist: } 17.62 \%(n=123) \\
\text { Presbyterian: } 14.61 \%(n=102) \\
\text { Protestant no denomination: } 10.32 \%(n=72) \\
\text { Episcopalian or Anglican: } 8.02 \%(n=56) \\
\text { Roman Catholic: } 6.88 \%(n=48) \\
\text { Evangelical: } 6.16 \%(n=43)\end{array}$ \\
\hline Born again or evangelical Christian? & $\begin{array}{l}\text { Yes: } 71.63 \%(n=500) \\
\text { No: } 28.37 \%(n=198)\end{array}$ \\
\hline $\begin{array}{l}\text { Size of Congregation on an Average } \\
\text { Worship Day }\end{array}$ & $\begin{array}{c}\text { 1-100 attendees: } 22.79 \%(n=157) \\
\text { 101-200: } 21.92 \%(n=151) \\
\text { 201-500: } 27.14 \%(n=187) \\
501-1000+: 28.16 \%(n=194)\end{array}$ \\
\hline Average service attendance & $\begin{array}{c}1 \text { or more service per year: } 1.34 \%(n=10) \\
1-3 \text { service per month: } 18.26 \%(n=136) \\
1 \text { or more service per week: } 80.4 \%(n=599)\end{array}$ \\
\hline Average activity attendance & $\begin{array}{c}1 \text { or more activity per year: } 22.68 \%(n=169) \\
1-3 \text { activity per month: } 37.58 \%(n=280) \\
1 \text { or more activity per week: } 39.73 \%(n=296)\end{array}$ \\
\hline $\begin{array}{l}\text { Estimated number of suicidal people } \\
\text { in faith community }\end{array}$ & $\begin{array}{l}\text { I don't know: } 63.56 \%(n=443) \\
0-5: 33.86 \%(n=236) \\
\text { 6-50+: } 2.58 \%(n=18)\end{array}$ \\
\hline Estimated number of suicide deaths & $\begin{array}{c}\text { I don't know: } 45.11 \%(n=314) \\
0-5: 52.59 \%(n=366) \\
\text { 6-50+: } 2.3 \%(n=16)\end{array}$ \\
\hline Estimated number of suicide funerals & $\begin{array}{c}\text { I don't know: } 57 \%(n=395) \\
0-5: 42.14 \%(n=292) \\
\text { 6-50+: } 0.87 \%(n=6)\end{array}$ \\
\hline Copycat suicides in faith community? & $\begin{array}{c}\text { I don't know: } 38.79 \%(n=270) \\
\text { Yes: } 2.01 \%(n=14) \\
\text { No: } 59.2 \%(n=412)\end{array}$ \\
\hline
\end{tabular}

Participants were on average middle aged $(\mathrm{M}=52.88, \mathrm{SD}=16.02)$. Most participants were female $(64 \%, n=449)$ and White $(89.11 \%, n=622)$, not Hispanic. Most were married $(75.64 \%, n=528)$, from 
the northeast $(38.29 \%, n=268)$, and Protestant $(85.62 \%, n=536)$. The most represented denomination was Baptist $(17.62 \%, n=123)$. A majority $(71.63 \%, n=500)$ described themselves as a born-again or evangelical Christian. The median size of congregation was 201-250 attendees on an average worship day and the mode was 251-500 attendees. Two questions were asked about participants' attendance: (1) How often do you attend a religious service in your faith community? (A religious service is a religious observation that includes rituals like the reading of sacred scripture.) (2) How often to you attend an activity in your faith community? (An activity is any event at your faith community other than a religious service, like a children's education meeting or social gathering.) Participants reported median attendance of one service per week and three activities per month in their faith community. Participants were also asked four questions about incidence of suicide in their faith community: (1) How many suicidal people are you aware of who participate in your faith community each year? (A suicidal person is someone who is thinking about suicide.) (2) How many suicide deaths that you are aware of have happened in your faith community since your faith community started? (3) Annually, how many suicide-related funerals happen in your faith community? (4) Has your faith community experience copycat suicides? (Copycat suicide is at least 2 or more suicides closely related in time and space.) Congregants reported that the median number of suicidal people in their faith community annually was $2-3$. The median number of suicide deaths in their faith community since the faith community started was 1 . The median number of annual suicide funerals in their faith community was 0 . Most respondents $(31.03 \%, n=215)$ reported 0 annual suicide funerals, 53 reported one annual suicide funeral, 11 reported 2-3 per year, and 13 reported $4-5$ per year. Most respondents $(59.2 \%, n=412)$ estimated that their faith community had not experienced copycat suicides. However, for all of the estimates mentioned above, a large portion of respondents said they did not know.

\subsection{Measures}

The Sense of Community Index-2 (SCI-2; (Chavis et al. 2008)) is a 24-item measure of sense of community with good internal consistency $(\alpha=0.94)$, with four subscales of 6 items each: met-needs, membership, influence and emotional connection (coefficient alpha scores ranging from 0.79 to 0.86 ). Whereas the SCI used true-false responses (Perkins et al. 1990), the SCI-2 uses a 4-point scale from 0 -not at all to 3-completely. Scores can range from 0 to 72 with higher scores indicating a greater sense of community. An additional item measured importance to feel a SOC on a scale from not important at all to very important: "How important is it to you to feel a sense of community with other community members?".

The Interpersonal Needs Questionnaire-15 (INQ; (Van Orden et al. 2012)) is a 15-item assessment of the belief about how much a person feels he or she belongs to others. The two subscales have good internal consistency: perceived burdensomeness (feeling one is a burden to others; 6 items; 0.85 to 0.90 ) and thwarted belongingness (feeling one does not belong to others; 9items; 0.81 to 0.87 , (Hill et al. 2015)). It uses a 7-point scale from 1-not at all true for me to 7-very true for me. Scores can range from 15 to 105 with higher scores indicating less overall belongingness.

The Depressive Symptom Inventory Suicidality subscale (DSI-SS; (Joiner et al. 2002)) is a 4-item brief screening for suicidal ideation with good internal consistency $(\alpha=0.90)$. It uses a 4-point scale. For example, for item A, the response options range from 0-I do not have thoughts of killing myself to 3-I always have thoughts of killing myself. Scores can range from 0 to 12 with higher scores indicating greater severity of suicidal ideation. Demographic items included questions about incidence of suicide in the faith community.

\subsection{Procedures}

We tested the first three hypotheses using correlations. We tested group differences using the Kruskal-Wallis (KW) equality-of-populations rank $\mathrm{H}$ test, a non-parametric chi square. KW results were confirmed by ANOVAs, because of ANOVA's robustness despite the violation of normality (Glass et al. 1972). ANOVAs yielded post-hoc Tukey tests. An exploratory backward stepwise 
regression examined predictors of current suicidal ideation as the dependent variable and age, gender, race, ethnicity, marital status, size of faith community, region, religion, service attendance, activity attendance, SOC and low overall belonging as independent variables. Analyses were conducted on the full study sample.

\section{Results}

On average, respondents reported that they "mostly" experience SOC with their faith community $(\mathrm{M}=46.9, \mathrm{SD}=12.72)$ and that on average it is important to them to feel a SOC $(\mathrm{M}=5.44, \mathrm{SD}=0.8)$ with their faith community members. In this sample, $11.41 \%(n=85)$ reported having thoughts of suicide.

\subsection{Psychometrics}

The SCI-2 had good reliability ( $\alpha=0.95)$, as did the subscales: met-needs $(\alpha=0.86)$, membership $(\alpha=0.79)$, influence $(\alpha=0.82)$, and emotional connection $(\alpha=0.88)$. The INQ also had good reliability $(\alpha=0.91)$, as did the subscales: perceived burdensomeness $(\alpha=0.91)$ and thwarted belongingness $(\alpha=0.89)$. The DSI-SS had good reliability $(\alpha=0.88)$.

\subsection{Hypothesis 1: SOC Is Related to Less Suicidal Ideation}

Suicidal ideation was negatively correlated to SOC $\left(\mathrm{r}=-0.11, p=0.003^{* *}\right)$ and to each of the SCI-2 subscales except membership. Congregants were divided into three groups of SOC: low, medium and high. Congregants with low SOC reported significantly more suicidal ideation $(\mathrm{M}=0.48, \mathrm{SD}=1.3)$ than congregants with high SOC $(\mathrm{M}=0.21, \mathrm{SD}=0.78), \mathrm{H}(2)=8.71, p=0.01$ **.

\subsection{Hypothesis 2: SOC and Belonging Are Positively Related}

SOC was negatively related to low overall belonging $\left(\mathrm{M}=25.64, \mathrm{SD}=13.56 ; \mathrm{r}=-0.3, p<0.0000^{* *}\right)$ and to each of the subscales: perceived burdensomeness $\left(\mathrm{M}=7.12, \mathrm{SD}=3.98 ; \mathrm{r}=-0.14, p=0.0002^{* *}\right)$ and thwarted belongingness $\left(\mathrm{M}=18.52, \mathrm{SD}=10.68 ; \mathrm{r}=-0.32, p<0.0000^{* *}\right)$. Each SCI-2 subscale was significantly and negatively correlated with overall belonging and each INQ subscale. Congregants with low SOC reported significantly lower overall belonging $(\mathrm{M}=30.91, \mathrm{SD}=16.64)$ than congregants with medium SOC $(\mathrm{M}=25.88, \mathrm{SD}=13.5)$, than congregants with high SOC $(\mathrm{M}=21.41, \mathrm{SD}=8.8)$, $\mathrm{H}(2)=62.84, p=0.0001^{* *}$.

\subsection{Hypothesis 3: Low Belonging Is Related to More Suicidal Ideation}

Suicidal ideation was related to low overall belonging $\left(\mathrm{r}=0.5, p<0.000{ }^{* *}\right)$, to perceived burdensomeness $\left(\mathrm{r}=0.6, p<0.0000^{* *}\right)$ and to thwarted belongingness $\left(\mathrm{r}=0.42, p<0.0000^{* *}\right)$. Congregants were divided into three groups of overall belonging: low, medium and high. Congregants with low overall belonging reported significantly more suicidal ideation $(\mathrm{M}=1.43, \mathrm{SD}=2.09)$ than congregants with medium overall belonging $(\mathrm{M}=0.16, \mathrm{SD}=0.66)$ or high overall belonging $(\mathrm{M}=0$, $\mathrm{SD}=0), \mathrm{H}(2)=99.22, p=0.0001^{* *}$.

\subsection{Research Question 4: Exploration of Gender and Religion Differences in Suicidal Ideation, SOC and Belonging}

No significant differences on suicidal ideation or SOC or SCI-2 subscales were found for male and female congregants. Female congregants rated feeling a sense of community with other faith members as significantly more important than males (females: $M=5.51, S D=0.75$; males: $M=5.37, S D=0.81$ ), $\mathrm{H}(1)=5.64, p=0.02 *$. Male congregants reported significantly more thwarted belongingness on the INQ thwarted belongingness subscale (males: $M=20.37, S D=10.17$; females: $M=18.61, S D=10.1$ ), $\mathrm{H}(1)=7.18, p=0.01^{* *}$. However, male participants did not report less overall belonging or more perceived burdensomeness. 
Jewish congregants reported significantly more suicidal ideation $(\mathrm{M}=1.03, \mathrm{SD}=1.77)$ than Catholic $(M=0.47, S D=1.34)$ and Protestant congregants $(M=0.24, S D=0.89), H(2)=17.67$, $p=0.0001^{* *}$. No significant differences were found for SOC between these groups. On the SCI-2 subscales, Protestant congregants reported significantly more met-needs $(\mathrm{M}=11.94, \mathrm{SD}=3.16)$ than Jewish congregants $(\mathrm{M}=10.11, \mathrm{SD}=3.84), \mathrm{H}(2)=9.87, p=0.01^{* *}$. Protestant congregants also reported significantly more sense of influence $(M=11.53, S D=3.08)$ than Catholic $(M=10.43, S D=3.69)$ and Jewish $(\mathrm{M}=9.97, \mathrm{SD}=4.13)$ congregants, $\mathrm{H}(2)=8.86, p=0.01^{* *}$. In addition, Protestant congregants rated feeling a sense of community with other faith community members as significantly more important to them $(\mathrm{M}=5.53, \mathrm{SD}=0.69)$ than Catholic $(\mathrm{M}=5.19, \mathrm{SD}=1.08)$ and Jewish congregants $(\mathrm{M}=5.11, \mathrm{SD}=0.99), \mathrm{H}(2)=12.22, p=0.002 * *$. No significant differences were found between religious traditions on the INQ or its subscales. However, size of congregation differed significantly among the three religious groups. Jewish congregants reporting significantly smaller congregational size (mode: 1-50 attendees on an average worship day) and Catholic congregants reporting significantly larger congregational size (mode: 1000+ attendees) than Protestant congregants (mode: 251-500 attendees), $\mathrm{H}(2)=51.33, p=0.0001$ **.

Exploratory backward stepwise regression eliminations were performed to find the most parsimonious set of predictors of suicidal ideation. Independent variables included age, gender, race, ethnicity, marital status, size of faith community, region, religion, service attendance, activity attendance, SOC and low overall belonging. The model (see Table 2) suggests that factors positively associated with suicidal ideation include: sense of community, identifying as Jewish or Hispanic, and low overall belonging. Negatively associated was attending three services a month or one a week, $\mathrm{F}(6,573)=48.76, p<0.0000^{* *}, \mathrm{R}^{2}=0.34$

Table 2. Predictors of suicidal ideation.

\begin{tabular}{cccccc}
\hline Predictors & Coefficient & $\mathbf{t}$ & $p$ & $\mathbf{9 5 \%}$ CI LL & 95\% CI UL \\
\hline Sense of Community & 0.01 & 3.34 & $0.001^{* *}$ & 0.004 & 0.02 \\
Identifying as Jewish & 0.48 & 2.95 & $0.003^{* *}$ & 0.16 & 0.8 \\
Attending 1 service/week & -0.22 & -2.61 & $0.009 * *$ & -0.38 & -0.05 \\
Identifying as Hispanic & 0.45 & 2.35 & $0.02 *$ & 0.07 & 0.83 \\
Low overall belonging & 0.05 & 15.51 & $0.000^{* *}$ & 0.04 & 0.05 \\
Attending 3 services/month & -0.27 & -2.34 & $0.02 *$ & -0.5 & -0.04 \\
\hline
\end{tabular}

${ }^{*}$ Indicates significance at $p \leq 0.5 ;{ }^{* *}$ Indicates significance at $p \leq 0.01 . \mathrm{F}(6,573)=48.76, p<0.0000{ }^{* *}, \mathrm{R}^{2}=0.34$.

To understand the positive association of SOC with suicidal ideation and because two levels of service attendance were omitted from the model during eliminations (attending two services per month and more than one service per week), congregants were divided into four groups, those attending on average two services per month, three services per month, one service per week, and more than one service per week. Significant differences were found between groups, $\mathrm{H}(3)=9.35, p=0.03$ * Post-hoc Tukey tests for suicidal ideation between those attending more than one service per week $(\mathrm{M}=0.51, \mathrm{SD}=1.32)$ and those attending one service per week $(\mathrm{M}=0.26, \mathrm{SD}=0.97)$ approached significance, $p=0.06$. No significant interaction effects between SOC and service attendance were found in a two-way ANOVA, but, in this significant model, $\mathrm{F}(11,717)=2.15, p=0.02 *$, post-hoc Tukey tests revealed that those attending more than one service per week reported significantly more suicidal ideation than those attending one service per week and those attending three services per month.

Additional analyses found that congregants attending more than one service per week reported significantly more SOC $(M=51.24, \mathrm{SD}=12.88)$ than those attending one service per week $(\mathrm{M}=47.17$, $\mathrm{SD}=11.61)$, than those attending three services per month $(\mathrm{M}=44.8, \mathrm{SD}=12.33)$, than those attending two services per month $(\mathrm{M}=38.3, \mathrm{SD}=10.26), \mathrm{H}(3)=34.63, p=0.0001^{* *}$. (Furthermore, those attending one service per week reported significantly more SOC than those attending two services per month.) A similar pattern was found for each of the SCI-2 subscales. Congregants attending more than one 
service per week reported that it was significantly more important to them to feel a sense of community with other faith community members $(\mathrm{M}=5.67, \mathrm{SD}=0.65)$ than those attending one service per week $(\mathrm{M}=5.47, \mathrm{SD}=0.72)$, than those attending three services per month $(\mathrm{M}=5.31, \mathrm{SD}=0.79)$, than those attending two services per month $(\mathrm{M}=5, \mathrm{SD}=0.79), \mathrm{H}(3)=32.35, p=0.0001^{* *}$. (Furthermore, those attending one service per week reported significantly more importance to them to feel a sense of community than those attending two services per month.) No significant differences were found between service attendance groups on the INQ and its subscales.

Congregants were also divided into three groups, those attending an activity at their faith community once or more a year but less than monthly, those attending one to three activities per month, and those attending one or more activities per week. No significant differences in suicidal ideation were found among groups. Congregants reported increasing SOC as they reported attending more activities. Those attending one or more activities per week reported significantly more SOC $(M=51.13$, $\mathrm{SD}=11.04)$ than those attending one to three activities per month $(\mathrm{M}=47.25, \mathrm{SD}=11.24)$, and than those attending one or more activities annually but not monthly $(\mathrm{M}=38.92, \mathrm{SD}=14.03), \mathrm{H}(2)=88.8$, $p=0.0001^{* *}$. A similar pattern was found for all four SCI-2 subscales. In addition, congregants attending one or more activities per week reported that it was significantly more important to them to feel a sense of community with other faith community members $(\mathrm{M}=5.7, \mathrm{SD}=0.62)$ than those attending one to three activities per month $(\mathrm{M}=5.46, \mathrm{SD}=0.72)$, than those attending once or more a year but less than monthly $(\mathrm{M}=4.98, \mathrm{SD}=0.98), \mathrm{H}(2)=85.11, p=0.0001 * *$. The three groups also differed on overall belonging with those attending one or more activities per week reporting significantly higher overall belonging $(\mathrm{M}=23.22, \mathrm{SD}=11.85)$ than those attending one to three activities per month $(\mathrm{M}=26.64, \mathrm{SD}=13.51)$, and than those attending one or more activities at their faith community a year but less than monthly $(\mathrm{M}=28.24, \mathrm{SD}=15.67), \mathrm{H}(2)=16.16, p=0.0003$ **. A similar result was found for the INQ thwarted belongingness subscale. For the perceived burdensomeness scale, congregants attending one or more activities per week reported significantly less perceived burdensomeness $(M=6.82, \mathrm{SD}=3.61)$ than those attending one or more activities at their faith community a year but less than monthly $(\mathrm{M}=7.86, \mathrm{SD}=5.05), \mathrm{H}(2)=6.34, p=0.04$ *

No differences in suicidal ideation or SOC were found for race. Only one SCI-2 subscale yielded significant differences. White congregants reported significantly more sense of influence $(M=11.33$, $\mathrm{SD}=3.33)$ than non-White congregants $(\mathrm{M}=10.55, \mathrm{SD}=2.88), \mathrm{H}(1)=4.66, p=0.03 *$. No significant differences between White and non-White congregants were found for importance to feel a sense of community or on overall belonging or thwarted belongingness or perceived burdensomeness. Hispanic congregants reported significantly more suicidal ideation $(\mathrm{M}=0.73, \mathrm{SD}=1.73)$ than Non-Hispanic congregants $(\mathrm{M}=0.3, \mathrm{SD}=1.01), \mathrm{H}(1)=3.73, p=0.05^{*}$. No significant differences on the SCI-2 or its subscales, importance to feel a sense of community, or the INQ or its subscales between Hispanic and Non-Hispanic respondents were found.

Married congregants reported significantly less suicidal ideation $(M=0.28, S D=0.98)$ than unmarried congregants $(\mathrm{M}=0.46, \mathrm{SD}=1.22), \mathrm{H}(1)=4.88, p=0.03 *$. They also reported significantly less SOC $(M=46.68, S D=12.13)$ than unmarried congregants $(M=48.9, S D=13.15), H(1)=4.52$, $p=0.03 *$. Only on one SCI-2 subscale were significant differences found. Unmarried congregants reported significantly more sense of membership $(M=11.86, S D=3.58)$ than married congregants $(\mathrm{M}=11.02, \mathrm{SD}=3.53), \mathrm{H}(1)=7.93, p=0.01 * *$. Unmarried congregants also reported it was significantly more important to them to feel a sense of community with other faith community members $(\mathrm{M}=5.59$, $\mathrm{SD}=0.72)$ than married congregants $(\mathrm{M}=5.42, \mathrm{SD}=0.79), \mathrm{H}(1)=9.07, p=0.003 * *$. Married congregants reported significantly more overall belonging $(\mathrm{M}=25.88, \mathrm{SD}=11.92)$ than unmarried congregants $(\mathrm{M}=29, \mathrm{SD}=14.74), \mathrm{H}(1)=6.21, p=0.01 * *$, including significantly less thwarted belongingness $(\mathrm{M}=18.74, \mathrm{SD}=9.78)$ than unmarried congregants $(\mathrm{M}=20.66, \mathrm{SD}=10.95), \mathrm{H}(1)=4.44, p=0.04$ *, and significantly less perceived burdensomeness $(\mathrm{M}=7.14, \mathrm{SD}=3.3)$ than unmarried congregants $(\mathrm{M}=8.34, \mathrm{SD}=4.98), \mathrm{H}(1)=19.61, p=0.0001$ **. 


\section{Discussion}

\subsection{Hypothesis 1: SOC Is Related to Less Suicidal Ideation}

Hypothesis 1 was somewhat supported. Congregants reporting high SOC also reported significantly less suicidal ideation. However, given the strong relationship between social disconnection and mortality (Holt-Lunstad et al. 2015), the correlation between SOC and suicidal ideation was unexpectedly weak and SOC was unexpectedly positively related to suicidal ideation in the exploratory backward stepwise regression. The weak correlation and positive relationship to suicidal ideation may be related to the 10 congregants who reported attending more than one service per week and also reported high SOC and some suicidal ideation. While VanderWeele et al. (2016) found that frequent religious service attendance was associated with substantially lower suicide risk and Rushing et al. (2013) found that more frequent attendance at religious activities was associated with decreased current suicidal ideation, a relationship which remained significant when social support was added to the model, in this sample it was not strongly related to lower suicidal ideation. Lawrence et al. (2016) have reported that religious service attendance is not especially protective against suicidal ideation. Contrary to Durkheim, Zhang (2016) has suggested that psychological strain, not social disconnectedness, is the etiological reason for SI. Because congregants who attend a service more than once a week also reported that it is important to them to feel a sense of community with other faith community members, it may be that more frequent service attendance attracts those for whom SOC is important and some of these congregants may experience suicidal ideation. It is interesting to note that activity attendance was not associated with suicidal ideation.

The weak correlation may also be related to the restricted range of congregants who attended at least two to three services per month. Had congregants who attended infrequently participated, the correlation may have been stronger.

To further examine the correlation between SOC and suicidal ideation, it may be important to include other conceptualizations of SOC such as size or degree of integration of social networks and quality of relationships, which may have separate and different effects on mortality (Holt-Lunstad et al. 2010, 2017). Stroope and Baker (2014) found that network density (number of close friends in the faith community) and church size had significant effects on feelings of group belonging in a church. Bryan and Hernandez (2013) found that the esteem-type of social support (i.e., feeling respected and valued) differentiated suicidal from non-suicidal Airmen.

It may also be important to examine whether the SCI-2 measures all that is unique about SOC in a faith community. Putnam (2000) wrote that "Faith communities in which people worship together are arguably the single most important repository of social capital in America" (p. 66). Carroll (2006) agreed, "Christians understand congregations to be a primary mode-arguably the primary mode- - through which the Christian gospel is organizationally embodied and made visible" (p. 11). However, it is not clear how a faith community might confer SOC differently from a non-religious/non-spiritual community such as a bowling league. Does a faith community's focus on spiritual transcendence larger than self, on altruistic behaviors, and on having a shared ontology as "a member of the family of God" contribute differently to SOC compared to other communities? It may be fruitful to understand how SOC manifests differently in a faith community and if a faith-specific SOC subscale of the SCI-2 may be needed. The uniqueness of faith-related SOC may suggest why the membership subscale of the SCI-2 was unrelated to suicidal ideation, in addition to its lower alpha compared to the other SCI-2 subscales.

The weak correlation may also be related to the different ways groups experience their connection to their faith community. Groups who reported high SOC or an element of SOC included those attending more than one service or one or more faith community activities per week (high SOC and high on all four elements); Protestant congregants (high met-needs and high sense of influence); and unmarried congregants (high sense of membership). It may be that different faith communities offer different types of SOC, or different groups may value SOC and its elements differentially. 
Unmarried congregants reported significantly more suicidal ideation. Divorced and separated persons have been found to be twice as likely to die by suicide as married people, with divorced men being twice as likely as married men to die by suicide (Kposowa 2000). Unmarried congregants also reported lower overall belonging, higher SOC and importance to feel a SOC with other faith community members than married congregants. This finding is similar to Wang et al. (2016) who found that religious faith was significantly and negatively related to suicidal behavior only at low levels of family support. It makes sense that groups with lower overall belonging may find it important to experience a SOC with faith community members. However, those attending a faith community activity once or more a year but less than monthly reported lower overall belonging and lower SOC and less importance to feel a SOC. It also makes sense that different groups apportion their SOC in different ways, fulfilling their need for connection in a variety of networks. For example, African-American men have been shown to be more likely than White men to visit or be visited by friends and to attend church or other group functions (Snowden 2001). In another study, older age was associated with smaller, less frequently seen, and less proximal networks that included more family; African-American participants had smaller networks, more contact with network members and more family in their networks (Ajrouch et al. 2001). This finding may also be related to cultural factors influencing the meaning of religion and spirituality in different ethnic groups (Johnstone et al. 2016). Since activity attendance was unrelated to suicidal ideation and the correlation between importance to feel a sense of community was more strongly correlated with activity attendance $(\mathrm{r}=0.37, p<0.0000)$ than with service attendance $(r=0.19, p<0.0000)$, it would be important to understand the different motivations for service attendance and activity attendance.

\subsection{Hypothesis 2: SOC and Belonging Are Positively Related}

This hypothesis was somewhat supported. Congregants with low SOC reported significantly lower overall belonging. However, SOC and belonging were moderately correlated, perhaps moderated by unmarried congregants who reported low overall belonging and high SOC. It may be that marital status more strongly influenced a congregant's sense of overall belonging than SOC in a faith community.

SOC was moderately related to thwarted belongingness and weakly related to perceived burdensomeness. It makes conceptual sense that the relationship between the thwarted belongingness subscale was stronger than the relationship to perceived burdensomeness, because the SCI-2 measures aspects of belonging, relatedness and emotional connection.

\subsection{Hypothesis 3: Low Belonging Is Related to More Suicidal Ideation}

Low overall belonging was strongly correlated to suicidal ideation. Perceived burdensomeness was more strongly related to suicidal ideation than thwarted belongingness, a finding which fits with previous research (Bryan and Hernandez 2013; Bryan et al. 2010; Van Orden et al. 2008). This finding also fits with the concept that burdensomeness is a necessary and key characteristic for suicidal ideation to develop (Van Orden et al. 2010), perhaps because it is not possible for one to feel belonging if one feels like a burden (Van Orden et al. 2012). Respondents reported significantly more thwarted belongingness $(\mathrm{M}=9.89, \mathrm{SD}=10.19)$ than perceived burdensomeness $(\mathrm{M}=1.36, \mathrm{SD}=3.71), \mathrm{t}(744)=27.13, p<0.0000$ ** It may be that faith communities protect against perceived burdensomeness by providing congregants with meaningful opportunities to contribute to the mission of the faith community.

It is of interest that of the four groups who reported significantly more suicidal ideation (those attending more than one service per week, those identifying as unmarried, Jewish or Hispanic), only those identifying as unmarried also reported low overall belonging. However, since marital status was eliminated from the exploratory backward stepwise regression and overall low belonging was not, overall low belonging was found to be a more significant predictor of suicidal ideation than marital status. 


\subsection{Research Question 4: Exploration of Gender and Religion Differences in Suicidal Ideation, SOC and Belonging}

Male respondents reported higher thwarted belongingness, which may have been related to congregations typically including more women than men in this sample and other nationally representative samples. This finding may also be related to loneliness being more common in males (Joiner 2011). It is of interest that female congregants assigned greater importance to feeling a sense of community with other faith community members, when all humans "are wired for-prepared for-togetherness" (Joiner 2011, p. 186). Because gender differences were not found in suicidal ideation, faith communities may protect men from suicidal ideation differently than women, or it may be that a sense of contributing (less perceived burdensomeness) may be more protective than belonging.

Jewish congregants reported significantly more suicidal ideation. While a few outliers can influence the mean of a small sample, congregants from the three religious traditions did not utilize the higher end of the range of the DSI-SS scale (maximum score for all respondents was 8 out of a possible 12) and the maximum score for four of the Jewish respondents was 5 . It may be that while religion may be protective for some groups, it may not be protective for all. Lawrence et al. (2016) suggest, "in countries or societies that oppose specific religions or religion-in-general, a person's religious beliefs and practices are less likely to protect against suicide" (p. 15). It should also be noted that $\mathrm{R} / \mathrm{S}$ may influence participants' perspective on the nature and causes of suicidal ideation given the influence of R/S on perspectives on depression (Trice and Bjorck 2006). Jewish respondents also did not report higher met-needs or sense of influence. They may experience their faith community differently because "going to church" is less emphasized in the Jewish tradition and "much of Judaism is celebrated in the home" (Rabbi Daniel Roberts, personal communication, 30 August 2017). Also, it may be that SOC as measured by the SCI-2 subscales in this study does not capture the unique experience of community among Jewish congregants. It may also be that Jewish respondents were more forthcoming in their report of suicidal ideation or that denominational affiliation may have influenced results. The sample included 1 Orthodox congregant, 19 Conservative congregants, 1 Reconstructionist congregant, 12 Reform congregants, and 1 other. Perhaps a different sample of Jewish respondents may have reported different levels of suicidal ideation.

It was not expected that Hispanics in the sample report more suicidal ideation because Hispanic adults responding to the National Survey on Drug Use and Health did not report higher rates of having serious thoughts of suicide as other adults in the U.S. population (Table 8.71B, Center for Behavioral Health Statistics and Quality 2016). Some studies have found greater suicidal ideation among Latina adolescents (Price and Khubchandani 2017) and a relationship between suicidal ideation and perceived discrimination and acculturative stress (Perez-Rodriguez et al. 2014).

\section{Limitations and Future Directions}

The primary limitation is that the study is based on the self-report of a convenience sample of primarily Protestant respondents, suggesting that a sample with broader representation of different religions could yield different results. Engaging congregants in general and Jewish congregants in particular was challenging. In a national survey of clergy and congregants, Carroll (2006) reported the clergy response rate was $72 \%$ of eligible pastors and $36 \%$ of congregations. Our experience was that some clergy were reluctant to send out a survey to their congregation on a highly stigmatized topic such as suicide. However, given the paucity of research in faith communities, the presence of suicide in faith communities, and suicidal people relying on clergy and their faith communities in times of suicidal crisis (Leane and Shute 1998; Mason et al. 2011; Wang et al. 2003), it is important to continue to study how religion protects against suicide. In addition, the study is cross-sectional, and therefore no conclusions about causation can be made.

Future possible research directions include population-based studies to understand if religions are differentially protective, especially "in countries or societies that oppose specific religions or religion-in-general" (Lawrence et al. 2016, p. 15). Population-based studies might also seek to 
understand in what networks different populations find connection, what portion of an individual's SOC comes from their faith community, and what type of SOC is needed to protect against suicidal ideation. For example, what type of SOC from a faith community might protect Jewish congregants from suicidal ideation. It would also be important to understand the higher suicidal ideation reported by Hispanic congregants, but not by other minority congregants, and to understand any possible association with perceived discrimination and acculturative stress. In addition, it would be fruitful to examine SOC multi-dimensionally to include network density, SOC, and quality of relationships. Another direction is to use qualitative methodologies to clarify what is unique about SOC in faith communities as different from, for example, SOC in a bowling league. Furthermore, it may be helpful to examine whether faith communities counteract perceived burdensomeness more than thwarted belongingness. Also, does attending services and activities confer different types of protection? The various protective aspects of religion may not be fully known, and qualitative methodologies are "especially useful when the researcher does not know the important variables to examine" (Creswell 2014, p. 20). Lastly, while this study focused on suicidal ideation, it is not clear how SOC might be related to suicide attempts and deaths, or if including less frequent attendees in the sample might result in a stronger correlation between SOC and suicidal ideation.

\section{Conclusions}

SOC was related, though weakly, to less suicidal ideation though attending more than one service per week was associated with more suicidal ideation. Congregants for whom SOC was more important to them attended more services and more activities. SOC was related to overall belonging, which was related to less suicidal ideation. Group differences were found. Male respondents reported higher thwarted belongingness and Jewish congregants reported more suicidal ideation. Demographic groups reported experiencing different elements of SOC. It may be that different faith communities offer different types of SOC, or different groups value SOC and its elements differentially. Future studies might examine the relationship of SOC to suicide attempts and deaths and how a faith community might confer SOC differently from a non-religious/non-spiritual community such as a bowling league.

Clinical and prevention implications are that faith communities may protect some people from suicidal thinking. Clinicians should consider asking about individual's connectedness to a supportive community when conducting a risk assessment for suicide. Moreover, since faith communities seem to function differently for various individuals, the clinician should be careful to avoid assumptions, and ask the individual to describe the degree and type of support they receive from their faith community.

Acknowledgments: The authors express appreciation to Monica Geist, for help with data analysis and to Rabbi Daniel Roberts for help with interpreting and understanding results.

Author Contributions: The first author conceptualized the study and developed the survey though all authors contributed. All authors recruited participants. The first author analyzed the data. All authors contributed to interpretation of the results. The second author formatted the article.

Conflicts of Interest: The authors declare no conflict of interests. They are all Protestant congregants.

Ethical Compliance: Gordon-Conwell Theological Seminary's institutional review board approved the study. At the beginning of the online survey hosted by SurveyMonkey, participants were given the names and contact information for the three authors and instructed to "call one of the researchers or the National Suicide Prevention Lifeline (1-800-273-TALK[8255]) or talk to your spiritual advisor or a counselor" if the survey causes distress. The National Suicide Prevention Lifeline number (1-800-273-TALK) was posted on each page of the survey. The names and contact information of the three authors were posted again at the end of the survey.

\section{References}

Ajrouch, Kristine J., Toni Claudette Antonucci, and Mary R. Janevic. 2001. Social networks among Blacks and Whites: The interaction between race and age. Journals of Gerontology: Series B 56: S112-18. [CrossRef]

Barranco, Raymond E. 2016. Suicide, religion, and Latinos: A macrolevel study of U.S. Latino suicide rates. The Sociological Quarterly 57: 256-81. [CrossRef] 
Bearman, Peter S., and James Moody. 2004. Suicide and friendships among American adolescents. American Journal of Public Health 94: 89-95. [CrossRef] [PubMed]

Blackmore, Emma R., Sarah Munce, Iris Weller, Brandon Zagorski, Stephen A. Stansfeld, and Donna E. Stewart. 2008. Psychosocial and clinical correlates of suicidal acts: Results from a national population survey. British Journal of Psychiatry 192: 279-84. [CrossRef] [PubMed]

Bryan, Craig J., and Ann M. Hernandez. 2013. The functions of social support as protective factors for suicidal ideation in a sample of Air Force personnel. Suicide and Life-Threatening Behavior 43: 562-73. [CrossRef] [PubMed]

Bryan, Craig J., Chad E. Morrow, Michael D. Anestis, and Thomas E. Joiner. 2010. A preliminary test of the interpersonal-psychological theory of suicidal behavior in a military sample. Personality and Individual Differences 48: 347-50. [CrossRef]

Burshtein, S., Bruce P. Dohrenwend, Itzhak Levav, Nomi Werbeloff, Michael Davidson, and Mark Weiser. 2016. Religiosity as a protective factor against suicidal behavior. Acta Psychiatrica Scandinavica 133: 481-88. [CrossRef] [PubMed]

Carroll, Jackson W. 2006. God's Potters: Pastoral Leadership and the Shaping of Congregations. Grand Rapids: William B. Eerdmans.

Center for Behavioral Health Statistics and Quality. 2016. Key Substance Use and Mental Health Indicators in the United States: Results from the 2015 National Survey on Drug Use and Health (HHS Publication No. SMA 16-4984, NSDUH Series H-51). Available online: https://www.samhsa.gov/data/sites/default/ files/NSDUH-DetTabs-2015/NSDUH-DetTabs-2015/NSDUH-DetTabs-2015.htm\#tab8-2a (accessed on 7 December 2017).

Chavis, David M., Kenneth S. Lee, and Joie D. Acosta. 2008. The Sense of Community (SCI) Revised: The Reliability and Validity of the SCI-2. Presented at the 2nd International Community Psychology Conference, Lisbon, Portugal, June 4-6.

Chioqueta, Andrea P., and Tore C. Stiles. 2007. The relationship between psychological buffers, hopelessness, and suicidal ideation: Identification of protective factors. Crisis 28: 67-73. [CrossRef] [PubMed]

Cohen, Sheldon, and Thomas A. Wills. 1985. Stress, social support, and the buffering hypothesis. Psychological Bulletin 98: 310-57. [CrossRef] [PubMed]

Cohen, Carl I., Yolonda Colemon, Robert Yaffee, and Georges J. Casimir. 2008. Racial differences in suicidality in an older urban population. Gerontologist 48: 71-78. [CrossRef] [PubMed]

Conner, Kenneth, Petter Britton, Luke M. Sworts, and Thomas E. Joiner. 2007. Suicide attempts among individuals with opiate dependence: The critical role of felt belonging. Addictive Behaviors 32: 1395-404. [CrossRef] [PubMed]

Cook, Joan M., Jane L. Pearson, Richard Thompson, Betty S. Black, and Peter V. Rabins. 2002. Suicidality in older African Americans: Findings from the EPOCH study. American Journal of Geriatric Psychiatry 10: 437-46. [CrossRef] [PubMed]

Creswell, John W. 2014. Research Design: Qualitative, Quantitative and Mixed Method Approaches, 4th ed. Thousand Oaks: Sage Publications.

Durkheim, Emile. 1897. Suicide: A Study in Sociology. Translated by John A Spaulding, and George Simpson. New York: Free Press.

Faith Communities Today. 2010. National Survey of Congregations. Available online: http:// faithcommunitiestoday.org/sites/default/files/2010FrequenciesV1.pdf (accessed on 25 May 2017).

Glass, Gene V., Percy D. Peckham, and James R. Sanders. 1972. Consequences of failure to meet assumptions underlying fixed effects analyses of variance and covariance. Review of Educational Research 42: 237-88. [CrossRef]

Greening, Leilani, and Laura Stoppelbein. 2002. Religiosity, attributional style, and social support as psychosocial buffers for African American and White adolescents' perceived risk for suicide. Suicide and Life-Threatening Behavior 32: 404-17. [CrossRef] [PubMed]

Hill, Ryan M., Yasmin Rey, Carla E. Marin, Carla Sharp, Kelly L. Green, and Jeremy W. Pettit. 2015. Evaluating the Interpersonal Needs Questionnaire: Comparison of the reliability, factor structure, and predictive validity across five versions. Suicide and Life-Threatening Behavior 45: 302-14. [CrossRef] [PubMed]

Hilton, Sterling C., Gilbert W. Fellingham, and Joseph L. Lyon. 2002. Suicide rates and religious commitment in young adult males in Utah. American Journal of Epidemiology 155: 413-19. [CrossRef] [PubMed] 
Holt-Lunstad, Julianne, Timothy B. Smith, and J. Bradley Layton. 2010. Social relationships and mortality risk: A meta-analytic review. PLoS Medicine 7: e1000316. [CrossRef] [PubMed]

Holt-Lunstad, Julianne, Timothy B. Smith, Mark Baker, Tyler Harris, and David Stephenson. 2015. Loneliness and social isolation as risk factors for mortality: A meta-analytic review. Perspectives on Psychological Science 10: 227-37. [CrossRef] [PubMed]

Holt-Lunstad, Julianne, Theodore F. Robles, and David A. Sbarra. 2017. Advancing social connection as a public health priority in the United States. American Psychologist 72: 517-30. [CrossRef] [PubMed]

Johnstone, Brick, Braj Bhushan, Robin Hanks, Dong Pil Yoon, and Daniel Cohen. 2016. Factor structure of the brief multidimensional measure of religiousness/spirituality in US and Indian samples with traumatic brain injury. Journal of Religion and Health 55: 572-86. [CrossRef] [PubMed]

Joiner, Thomas. 2005. Why People Die by Suicide. Cambridge: Harvard University Press.

Joiner, Thomas E. 2011. Lonely at the Top: The High Cost of Men's Success. New York: Palgrave MacMillan.

Joiner, Thomas E., Jon J. Pfaff, and John G. Acres. 2002. A brief screening tool for suicidal symptoms in adolescents and young adults in general health settings: Reliability and validity data from the Australian National General Practice Youth Suicide Prevention Project. Behaviour Research and Therapy 40: 471-81. [CrossRef]

Joiner, Thomas E., Daniel Hollar, and Kimberly Van Orden. 2006. On Buckeyes, Gators, Super Bowl Sunday, and the Miracle on Ice: "Pulling together" is associated with lower suicide rates. Journal of Social Clinical Psychology 25: 179-95. [CrossRef]

Joiner, Thomas E., Kimberly A. Van Orden, Tracy K. Witte, Edward A. Selby, Jessica D. Ribeiro, Robyn Lewis, and David M. Rudd. 2009. Main predictions of the interpersonal-psychological theory of suicidal behavior: Empirical tests in two samples of young adults. Journal of Abnormal Psychology 118: 634-46. [CrossRef] [PubMed]

Kazi, Tasnim B., and Sorjini Naidoo. 2016. Does religiosity mediate suicidal tendencies? A South African study of Muslim tertiary students. Journal of Religion and Health 55: 1010-23. [CrossRef] [PubMed]

Kissil, Karni, and Haya Itzhaky. 2015. Experiences of the Orthodox community among Orthodox Jewish gay men. Journal of Gay \& Lesbian Social Services: The Quarterly Journal of Community E Clinical Practice 27: 371-89.

Kitchen, Peter, Allison Williams, and James Chowhan. 2012. Sense of belonging and mental health in Hamilton, Ontario: An Intra-urban analysis. Social Indicators Research 108: 277-97. [CrossRef]

Kleiman, Evan M., and Richard T. Liu. 2013. Social support as a protective factor in suicide: Findings from two nationally representative samples. Journal of Affective Disorders 150: 540-45. [CrossRef] [PubMed]

Koenig, Harold G., Dana E. King, and Verna Benner Carson. 2012. Handbook of Religion and Health. Oxford: Oxford University Press.

Kposowa, Augustine J. 2000. Marital status and suicide in the National Longitudinal Mortality Study. Journal of Epidemiology Community Health 54: 254-61. [CrossRef] [PubMed]

Kralovec, Karl, Sabine Kunrath, Clemens Fartacek, Eva-Maria Pichler, and Martin Plöderl. 2017. The genderspecific associations between religion/spirituality and suicide risk in a sample of Austrian psychiatric inpatients. Suicide and Life-Threatening Behavior. [CrossRef] [PubMed]

Kuo, Frances E., William C. Sullivan, Coley Rebekah Levine, and Liesette Brunson. 1998. Fertile ground for community: Inner-city neighborhood common spaces. American Journal of Community Psychology 26: 823-51. [CrossRef]

Lawrence, Ryan E., David Brent, K. J. Mann, Ainsley F. Burke, Michael C. Grunebaum, Hanga A. Galfalvy, and Maria A. Oquendo. 2016. Religion as a risk factor for suicide attempt and suicide ideation among depressed patients. Journal of Nervous and Mental Disease 204: 845-50. [CrossRef] [PubMed]

Lawrence, Ryan E., Maria A. Oquendo, and Barbara Stanley. 2016. Religion and suicide risk: A systematic review. Archives of Suicide Research 20: 1-21. [CrossRef] [PubMed]

Leane, Wendy, and Rosalyn Shute. 1998. Youth suicide: The knowledge and attitudes of Australian teachers and clergy. Suicide and Life-Threatening Behavior 28: 165-73. [PubMed]

Lim, Chaeyoon, and Robert Putnam. 2010. Religion, social networks, and life satisfaction. American Sociological Review, 75: 914-33. [CrossRef]

Mahan, Beverly B., Wendy M. Garrard, Susan E. Lewis, and John R. Newbrough. 2002. Sense of community in a university setting: Campus as workplace. In Psychological Sense of Community: Research, Applications, and Implications. Edited by Adrian T. Fisher, Christopher C. Sonn, and Brian J. Bishop. New York: Kluwer Academic/Plenum Publishers, pp. 123-40. 
Mason, K., P. Polischuk, R. Pendleton, E. Bousa, R. Good, and J. D. Wines Jr. 2011. Clergy referral of suicidal individuals: A qualitative study. Journal of Pastoral Care E Counseling 65: 1-11.

Maulik, Pallab K., William W. Eaton, and Catherine P. Bradshaw. 2011. The effect of social networks and social support on mental health services use, following a life event, among the Baltimore epidemiologic catchment area cohort. Journal of Behavioral Health Services Research 38: 29-50. [CrossRef] [PubMed]

McConnell, David, Lyndsey Hahn, Amber Savage, Camille Dubé, and Elly Park. 2016. Suicidal ideation among adults with disability in Western Canada: A Brief report. Community Mental Health Journal 52: 519-26. [CrossRef] [PubMed]

McMillan, David W., and David M. Chavis. 1986. Sense of community: A definition and theory. Journal of Community Psychology 14: 6-23. [CrossRef]

Miers, Ron, and Adrian T. Fisher. 2002. Being church and community: Psychological sense of community in a local parish. In Psychological Sense of Community: Research, Applications, and Implications. Edited by Adrian T. Fisher, Christopher C. Sonn, and Brian J. Bishop. New York: Kluwer Academic/Plenum Publishers, pp. 143-60.

Moak, Z. B., and A. Agrawal. 2010. The association between perceived interpersonal social support and physical and mental health: Results from the national epidemiological survey on alcohol and related conditions. Journal of Public Health 32: 191-201. [CrossRef] [PubMed]

Morton, Kelly R., Jerry W. Lee, and Leslie R. Martin. 2017. Pathways from religion to health: Mediation by psychosocial and lifestyle mechanism. Psychology of Religion and Spirituality 9: 106-17. [CrossRef] [PubMed]

Nisbet, Paul A., Paul R. Duberstein, Yeates R. Conwell, and Larry R. Seidlitz. 2000. The effect of participation in religious activities on suicide versus natural death in adults 50 and older. Journal of Nervous and Mental Disease 188: 543-46. [CrossRef] [PubMed]

Nonnemaker, James M., Clea A. Mcneely, and Robert William Blum. 2003. Public and private domains of religiosity and adolescent health risk behaviors: Evidence from the National Longitudinal Study of Adolescent Health. Social Science and Medicine 57: 2049-54. [CrossRef]

O'Reilly, Dermot, and Michael Rosato. 2015. Religion and the risk of suicide: Longitudinal study of over 1 million people. The British Journal of Psychiatry 206: 466-70. [CrossRef] [PubMed]

Perez-Rodriguez, M. Mercedes, Enrique Baca-Garcia, Maria A. Oquendo, Shuai Wang, Melanie M. Wall, Shang-Min Liu, and Carlos Blanco. 2014. Relationship between acculturation, discrimination, and suicidal ideation and attempts among US Hispanics in the National Epidemiologic Survey of Alcohol and Related Conditions. Journal of Clinical Psychiatry 75: 399-407. [CrossRef] [PubMed]

Perkins, Douglas D., Paul Florin, Richard C. Paul, David A. Wandersman, and David M. Chavis. 1990. Participation and the social and physical environment of residential blocks: Crime and community context. American Journal of Community Psychology 18: 83-115. [CrossRef]

Pienaar, Jacobus, Sebastiaan Rothmann, and Fons J. R. Van De Vijver. 2007. Occupational stress, personality traits, coping strategies, and suicide ideation in the South African police service. Criminal Justice and Behavior 34: 246-58. [CrossRef]

Piscopo, Kathryn, Rachel N. Lipari, Jennifer Cooney, and Cristie Glasheen. 2016. Suicidal Thoughts and Behavior among Adults: Results from the 2015 National Survey on Drug Use and Health. Available online: https:// www.samhsa.gov/data/sites/default/files/NSDUH-DR-FFR3-2015/NSDUH-DR-FFR3-2015.htm (accessed on 15 January 2018).

Price, James H., and Jagdish Khubchandani. 2017. Latina adolescents health risk behaviors and suicidal ideation and suicide attempts: Results from the National Youth Risk Behavior Survey 2001-2013. Journal of Immigrant and Minority Health 19: 533-42. [CrossRef] [PubMed]

Putnam, Robert D. 2000. Bowling Alone: The Collapse and Revival of American Community. New York: Simon and Schuster.

Rasic, Daniel T., Shay-Lee Belik, Brenda Elias, Laurence Y. Katz, Murray Enns, and Jitender Sareen. 2009. Spirituality, religion, and suicidal behavior in a nationally representative sample. Journal of Affective Disorders 114: 32-40. [CrossRef] [PubMed]

Rushing, Nicole C., Elizabeth Corsentino, Jennifer L. Hames, Natalie Sachs-Ericsson, and David C. Steffans. 2013. The relationship of religious involvement indicators and social support to current and past suicidality among depressed older adults. Aging Mental Health 17: 366-74. [CrossRef] [PubMed]

Snowden, Lonnie R. 2001. Barriers to effective mental health services for African Americans. Mental Health Services Research 3: 181-87. [CrossRef] [PubMed] 
Stroope, Samuel, and Joseph O. Baker. 2014. Structural and cultural sources of community in American congregations. Social Science Research 45: 1-17. [CrossRef] [PubMed]

Thompson, Martie P., Ching-Hua Ho, and Jeffrey B. Kingree. 2007. Prospective associations between delinquency and suicidal behaviors in a nationally representative sample. Journal of Adolescent Health 40: 232-37. [CrossRef] [PubMed]

Trice, Pamela D., and Jeffrey P. Bjorck. 2006. Pentecostal perspectives on causes and cures of depression. Professional Psychology: Research and Practice 37: 283-94. [CrossRef]

Tsai, Alexander C., Michel Lucas, and Ichiro Kawachi. 2015. Association between social integration and suicide among women in the United States. JAMA Psychiatry 72: 987-93. [CrossRef] [PubMed]

U.S. Congregational Life Survey. 2001. Welcoming New People and Helping Them Feel They Belong. Available online: http:/ / www.uscongregations.org/blog/2014/02/17/welcoming-new-people-and-helping-themfeel-they-belong-2/ (accessed on 25 May 2017).

Van Orden, Kimberly A., Tracy K. Witte, Kathryn H. Gordon, Theodore W. Bender, and Thomas E. Joiner. 2008. Suicidal desire and the capability for suicide: Tests of the interpersonal-psychological theory of suicidal behavior among adults. Journal of Consulting and Clinical Psychology 76: 72-83. [CrossRef] [PubMed]

Van Orden, Kimberly A., Tracy K. Witte, Lisa M. James, Yessenia Castro, Kathryn H. Gordon, Scott R. Braithwaite, and Thomas E. Joiner. 2008. Suicidal ideation in college students varies across semesters: The mediating role of belongingness. Suicide and Life-Threatening Behavior 38: 427-35. [CrossRef] [PubMed]

Van Orden, Kimberly A., Tracy K. Witte, Kelly C. Cukrowicz, Scott R. Braithwaite, Edward A. Selby, and Thomas E. Joiner. 2010. The interpersonal theory of suicide. Psychological Review 117: 575-600. [CrossRef] [PubMed]

Van Orden, Kimberly A., Kelly C. Cuckrowicz, Tracy K. Witte, and Thomas E. Joiner. 2012. Thwarted belongingness and perceived burdensomeness: Construct validity and psychometric properties of the Interpersonal Needs Questionnaire. Psychological Assessment 24: 197-215. [CrossRef] [PubMed]

VanderWeele, Tyler J., Shanshan Li, Alexander C. Tsai, and Ichiro Kawachi. 2016. Association between religious service attendance and lower suicide rates among US women. JAMA Psychiatry 73: 845-51. [CrossRef] [PubMed]

Vieten, Cassandra, Shelly Scammell, Ron Pilato, Ingrid Ammondson, Kenneth I. Pargament, and David Lukoff. 2013. Spiritual and religious competencies for psychologists. Psychology of Religion and Spirituality 5: 129-44. [CrossRef]

Wang, Phillip S., Patricia A. Berglund, and Ronald C. Kessler. 2003. Patterns and correlates of contacting clergy for mental disorders in the United States. Health Services Research 38: 647-73. [CrossRef] [PubMed]

Wang, Mei-Chuan, Joel Y. Wong, Pius N. Nyutu, Angela Spears, and Wilbert I. Nichols. 2016. Suicide protective factors in outpatient substance abuse patients: Religious faith and family support. International Journal for the Psychology of Religion 26: 370-81. [CrossRef]

Wilchek-Aviad, Yael, and Michal Malka. 2016. Religiosity, meaning in life and suicidal tendency among Jews. Journal of Religion and Health 55: 480-94. [CrossRef] [PubMed]

Woolever, Cynthia, and Deborah Bruce. 2004. Beyond the Ordinary: Ten Strengths of U.S. Congregations. Louisville: Westminster John Knox Press.

You, Sungeun, Kimberly A. Van Orden, and Kenneth R. Conner. 2011. Social connections and suicidal thoughts and behavior. Psychology of Addictive Behaviors 25: 180-84. [CrossRef] [PubMed]

Zhang, Jie. 2016. From psychological strain to disconnectedness: A two-factor model theory of suicide. Crisis: The Journal of Crisis Intervention and Suicide Prevention 37: 169-75. [CrossRef] [PubMed]

(c) 2018 by the authors. Licensee MDPI, Basel, Switzerland. This article is an open access article distributed under the terms and conditions of the Creative Commons Attribution (CC BY) license (http://creativecommons.org/licenses/by/4.0/). 